\title{
ARTIGOS
}

\section{O novo desenvolvimentismo e a decadência ideológica do pensamento econômico brasileiro}

\author{
The new developmentalism and the ideological \\ decadence of the Brazilian economic thinking
}

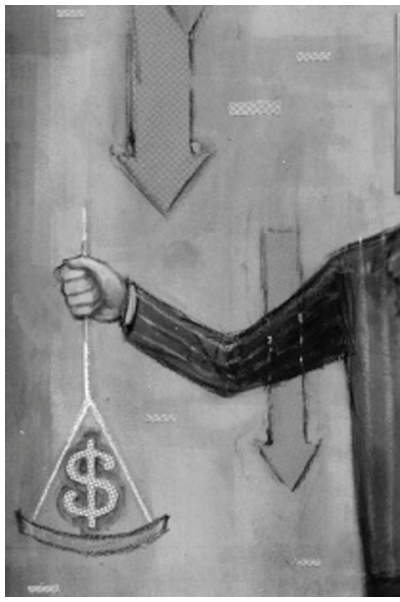

Rodrigo Castelo*

Resumo: No neoliberalismo, o Brasil experimenta uma nova fase do desenvolvimento capitalista que se inicia nos governos FHC e se aprofunda sob a direção dos governos Lula e Dilma. Na esteira das transformações estruturais, constata-se o surgimento de uma ideologia que se propõe como guia dos rumos do desenvolvimento capitalista brasileiro, o novo desenvolvimentismo. O presente artigo é uma contribuição à crítica da economia política brasileira contemporânea, explicitando seus limites a partir do conceito marxiano (e luckásiano) de decadência ideológica.

Palavras-chave: Novo desenvolvimentismo. Decadência ideológica. Crítica da economia política.

\begin{abstract}
In neoliberalism times, Brazil has experienced a new phase of capitalist development that began in FHC's era and deepened under Lula and Dilmas's leadership. Following the structural changes, there is the emergence of an ideology as a guide to direct the capitalist development in Brazil - the new developmentalism. This article is a contribution to the critique of contemporary Brazilian political economy, and it explains its limits from the Marxian's (and luckasian) concept of ideological decadence.
\end{abstract}

Keywords: New developmentalism. Ideological decadence. Critique of political economy.

\footnotetext{
* Professor da Universidade Estadual do Rio de Janeiro (Uerj) e Universidade Federal do Estado do Rio de Janeiro (Unirio), Brasil, pesquisador do Laboratório de Estudos Marxistas José Ricardo Tauile (Lema/UFRJ).

E-mail: rodrigo.castelo@gmail.com.
} 
Constitui já uma regra o fato de todas as correntes, que, com a ajuda do prefixo "neo", se reclamam de uma escola reconhecida como clássica, aproveitarem desta os seus elementos retrógrados e esvaziarem-na cuidadosamente do que era nela a expressão de uma real grandeza (Adam Schaff)

\section{Introdução}

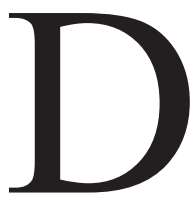

esde os anos 1930 o nacional-desenvolvimentismo exerceu uma forte influência ideológica e política nos principais debates da agenda nacional, até o seu ocaso nos anos 1990 com a ascensão do neoliberalismo. A partir do segundo mandato do governo Lula (2007-10), com o aumento das taxas de crescimento econômico e a tímida melhora de alguns indicadores sociais, a ideologia desenvolvimentista voltou repaginada à cena - acoplada dos prefixos "novo" e "social" — e tornou-se o tema da moda no Brasil.

A nova fase do desenvolvimento capitalista inaugurada nos governos do Partido dos Trabalhadores (PT) foi comemorada pelas classes dominantes. Em 2006, Olavo de Setúbal, dono do Itaú, fez rasgados elogios à política econômica do governo Lula, que então mantinha intacta a herança dos governos Fernando Henrique Cardoso do tripé defendido pelo Consenso de Washington (superávit primário, metas inflacionárias e câmbio flutuante). Em novembro de 2009, a revista The Economist fez uma matéria de capa com o título "Brasil decola" (Brazil takes off), com a imagem do Cristo Redentor subindo aos céus como um moderno foguete. Em março de 2011, Luiz Carlos Bresser Pereira escreveu que "estamos todos felizes com a nossa presidenta", fazendo adendos críticos às políticas de câmbio e juros sobrevalorizados. E, em janeiro de 2012, o banqueiro Roberto de Setúbal, herdeiro de Olavo, declarou o seguinte a respeito da política econômica do governo Dilma: "Gosto de tudo o que tenho visto". No interior das classes dominantes (e seus aliados nacionais e internacionais), criou-se um clima de otimismo sobre os rumos do desenvolvimento capitalista, que também é alimentado pelo apassivamento das lutas da classe trabalhadora gerado pelo transformismo do PT. Otimismo mais do que justificado, tendo em vista que lucros e juros capitalistas bateram recordes nos últimos anos. 
Esse clima de otimismo, que muitas vezes descamba para uma apologética vulgar do capitalismo nacional, espraiou-se por outros grupos sociais, em particular intelectuais tradicionais de peso na academia e intelectuais orgânicos de partidos outrora de esquerda. Segundo o bloco ideológico novo desenvolvimentista, o Brasil viveria uma etapa do desenvolvimento capitalista inédita por conjugar crescimento econômico e justiça social - o que inauguraria um original padrão de acumulação no país, o social-desenvolvimentismo - e, no limite, por apontar para o rompimento com o neoliberalismo ou o subdesenvolvimento. Emir Sader defende há anos que a América Latina vive uma fase pós-neoliberal; Maria da Conceição Tavares declarou, em entrevista a "Folha de S.Paulo" em setembro de 2010, que "desta vez [...] a maldição do Furtado, que era desenvolvimento junto com subdesenvolvimento, pode terminar"; e Márcio Pochmann afirmou, em entrevista a mesma Folha em novembro, que o social-desenvolvimentismo é um padrão de acumulação que rompe com a financeirização e cria um Estado de bem-estar social no país!

É sobre esse conjunto de intelectuais, suas ideologias e aparelhos privados e estatais de hegemonia que versa o presente artigo. O objetivo é apresentar o novo desenvolvimentismo a partir da sua processualidade histórica e suas contradições internas. Em artigo publicado no livro Encruzilhadas da América Latina no século XXI (Castelo, 2010), limitei-me ao estudo da decadência ideológica do novo desenvolvimento na sua corrente pós-keynesiana. No presente artigo, inteiramente inédito, além de aprofundar o estudo sobre Marx e a história do pensamento econômico, atualizo e estendo a análise, sob o referencial teórico da crítica da economia política, para outras correntes do novo desenvolvimento, a saber, a macroeconomia estruturalista do desenvolvimento e a social-desenvolvimentista.

\section{Marx e a decadência ideológica da economia política}

Desde os primeiros escritos em parceria com Engels, notadamente $A$ sagrada família (1845) e $A$ ideologia alemã (1846), Marx relacionou a sistematização das ideologias e com o contexto histórico das lutas de classes e do desenvolvimento das forças produtivas e das relações sociais de produção. Até 
então os produtos da consciência humana eram considerados, em larga medida, frutos da revelação divina ou da genialidade de um indivíduo. O método marxiano de estudo do ser social, chamado de materialismo histórico, foi construído a partir da crítica à ideologia alemã e reafirmado no período da crítica da economia política. Resumidamente, temos o materialismo histórico nas palavras do próprio Marx (1859-1982, p. 25):

O resultado geral a que cheguei e que, uma vez obtido, seguiu-me de fio condutor aos meus estudos, pode ser formulado em poucas palavras: na produção social da própria vida, os homens contraem relações determinadas, necessárias e independentes de sua vontade, relações de produção estas que correspondem a uma etapa determinada de desenvolvimento das suas forças produtivas materiais. A totalidade dessas relações de produção forma a estrutura econômica da sociedade, a base real sobre a qual levanta uma superestrutura jurídica e política, e à qual correspondem formas sociais determinadas da consciência. O modo de produção da vida material condiciona o processo em geral de vida social, político e espiritual. Não é a consciência dos homens que determina o seu ser, mas, ao contrário, é o seu ser social que determina sua consciência.

No livro Para a crítica da economia política (1859-1982), Marx realiza uma digressão sobre as teorias econômicas que discutem o tema do valor e encontram o trabalho como fonte da riqueza material, proposição tida por Marx (p. 49) como "a lei fundamental da economia política moderna". Os marcos iniciais dessa linhagem do pensamento econômico são as obras de William Petty e Pierre de Boisguillebert e o seu término encontra-se nos livros de David Ricardo, considerado o auge da economia política, e Simonde de Sismondi, precursor da crítica (utópica e romântica) da economia burguesa.

Nas Teorias da mais-valia (1862-3), tomo IV de O capital, Marx introduz o conceito de economia vulgar na sua história do pensamento econômico. $\mathrm{O}$ que distinguiria um economista clássico de um vulgar seria a diferença teórico-analítica sobre a formação do preço de uma mercadoria. Os clássicos entendem que o preço de uma mercadoria é formado pela soma da renda fundiária, do lucro e do salário. Os vulgares, por sua vez, numa operação ideológica significativa, retiram o lucro derivado das operações industriais e introduzem o juro na formação dos preços. Ao fazerem isto, cortam a relação do preço com 
a produção industrial, isto é, com o trabalho, e passam a cultivar o fetiche do dinheiro que se reproduziria por si mesmo, a famosa fórmula D-D' (Marx, [1862-3]-1982, p. 218-33). Jean Baptiste Say e Frédéric Bastiat foram representantes significativos da economia vulgar.

Anos mais tarde, no posfácio à segunda edição alemã (1873) de $O$ capital, o revolucionário alemão refinou as suas anotações sobre a história do pensamento econômico e retomou os princípios metodológicos do materialismo histórico, relacionando as ideologias às lutas de classes. ${ }^{2}$ Segundo Marx, a economia política clássica foi fruto da ascensão econômica, política e cultural da burguesia na Europa Ocidental, em particular nos países onde ocorreram as principais revoluções políticas e econômicas, como Inglaterra e França. No plano político, o centro das lutas de classes estava circunscrito aos embates da burguesia com os senhores feudais. O proletariado ainda não tinha se constituído como uma classe autônoma e, por isso, atuava como uma linha de força auxiliar da burguesia no seu projeto revolucionário de tomada do poder. No plano econômico, a revolução industrial estava a pleno vapor, e o trabalho precisava ser dominado pelo capital nos processos de produção.

Enquanto classe revolucionária, a burguesia tinha o interesse em desvelar a realidade nos seus recônditos mais secretos, e o trabalho, elemento essencial da base econômica, era alvo dos estudos objetivos e desinteressados dos economistas políticos, representantes ideológicos da classe burguesa. Ou seja, para Marx, a partir do final do século XVII até o início do XIX, os ideólogos burgueses - Petty, Smith, Ricardo - produziram obras do mais alto nível científico, revelando alguns elementos essenciais da realidade em transformação a partir das suas teorias do valor-trabalho, embora tantos outros tenham ficado ocultos, como a historicidade dos modos de produção. Marx sempre criticou o método dos economistas burguesas - clássicos ou vulgares - que naturaliza as relações sociais de produção.

O caráter objetivo e científico da economia política desapareceu justamente no momento em que a supremacia burguesa foi conquistada. Desde 1830, quando a burguesia tornou-se a classe dominante na França e na Inglaterra e o

2. Para um estudo mais aprofundado da relação entre história do pensamento econômico, ideologia e método na obra de Marx, cf. Malta e Castelo (2012). 
proletariado emergiu como um sujeito histórico politicamente organizado em torno de associações coletivas e com relativa autonomia ideológica, a concepção burguesa do mundo viveu uma fase apologética, pois foi obrigada a ocultar as principais contradições do modo de produção capitalista, mistificando-o como uma ordem natural, para conservar o status quo ameaçado pelas lutas socialistas. Desse cenário histórico adveio a crise decisiva da economia burguesa, na qual se inicia a sua decadência ideológica ${ }^{3}$. O caráter vulgar e apologético do liberalismo residiu precisamente no ocultamento das contradições provenientes da esfera da produção, limitando-se ao estudo no nível das aparências, entendidas como a esfera da circulação das mercadorias.

No período da decadência ideológica da burguesia, a economia política se bifurcou em dois ramos: a economia vulgar, com seus sicofantas diligentes na defesa dos interesses das classes dominantes às custas da sua reputação científica, e a economia política do socialismo burguês, estampada no "oco sincretismo" de John Stuart Mill que objetivava harmonizar a teoria burguesa com algumas demandas da classe trabalhadora, "agora impossíveis de ignorar" (Marx, 1873-2003, p. 24).

Na história marxiana do pensamento econômico, John Stuart Mill foi avaliado como um pensador eclético medíocre, "com escassas e pobres pesquisas originais" (Marx, 1867-2003, p. 151). Quando surgem elogios, é na forma do seu habitual sarcasmo: "na planura imensa, montículos de terra parecem colinas" (Idem, p. 587). No mesmo ano da Primavera dos Povos, Mill publicou Princípios de economia política, uma combinação eclética entre as teorias clássicas de Smith e Ricardo com as proposições apologéticas da economia vulgar, como a teoria de Senior sobre lucro e abstinência (Napoleoni, 1982, p. 121). O inédito hasteamento da bandeira vermelha do socialismo produziu uma intimidação nas classes dominantes e um setor da ideologia burguesa passou a teorizar a "conciliação do inconciliável" por meio de uma fórmula eclética, visando cooptar parte da classe adversária por meio do atendimento pontual de suas reivindicações. Anos depois, o economista inglês escreveu sobre o socialismo, recuando das suas antigas críticas ao movimento dos trabalhadores, colocando-se como um mediador entre o liberalismo e o socialismo.

3. Sobre o conceito de decadência ideológica nas obras de Marx, ver György Lukács (1938-2010). 
Marx, dessa forma, fundamenta duplamente o seu conceito de crítica às ideologias burguesas: primeiro, relaciona a ideologia ao seu tempo histórico e as suas principais determinações econômicas e políticas e, segundo, faz um profundo estudo da estrutura analítica e metodológica das teorias, examinando os seus nexos internos e apontando seus limites intrínsecos, bem como relacionando a obra com a concepção do mundo do autor e seus interesses (diretos ou indiretos) de classe. No caso da crítica da economia política, Marx relaciona o início e o auge dessa escola teórica ao período revolucionário da burguesia na luta de classes, e a sua decadência ao período conservador. No plano analítico, constrói a controvérsia entre clássicos, vulgares e críticos da economia política a partir do uso ou do abandono da teoria do valor-trabalho, bem como do método de naturalizar ou historicizar as relações sociais de produção em geral.

\section{Do nacional ao novo desenvolvimentismo}

O nacional-desenvolvimentismo percorreu um longo caminho na história do pensamento econômico brasileiro. Pedro Fonseca (2004) assinala que essa ideologia surgiu como uma mistura eclética de diferentes escolas teóricas, a saber, o nacionalismo, o protecionismo industrial, o papelismo e o positivismo. Do ponto de vista político, a primeira experiência desenvolvimentista ocorreu em 1928 com o governo Vargas no estado do Rio Grande do Sul. Ricardo Bielschowsky (1995) identifica essa origem com Vargas ocupando a presidência em 1930.

O processo de industrialização via o modelo de substituição de importações ganhou impulso em 1930 como forma de reação à crise econômica mundial de 1929. Esse projeto de industrialização começou sob impulso de iniciativas estatais, com políticas protecionistas, de empréstimos e isenções fiscais para investidores privados, que então alocavam seus capitais nos setores de bens de consumo não duráveis. Operou-se, desse modo, a articulação de um novo bloco de poder, com uma aliança entre o Estado e uma burguesia nacional emergente, sem, contudo, romper totalmente com as antigas classes dominantes, notadamente os latifundiários. Daí a Revolução de 1930 liderada por Vargas ser caracterizada como uma revolução passiva (Coutinho, 1999, p. 196-202), com acordos entre as novas e velhas classes dominantes que operam a consolidação 
do capitalismo no Brasil em paralelo com a manutenção de antigas estruturas coloniais, com destaque para algumas expressões da "questão social", como a agrária, a racial e a democrática. Assim sendo, a formação econômico-social brasileira foi forjada pelo desenvolvimento desigual e combinado entre distintos modos de produção, no qual o capitalismo detém o controle econômico, político e cultural frente aos demais.

Todavia, o auge do desenvolvimentismo ocorreu nos anos 1950-60. Nesse período, o modelo desenvolvimentista aprofundou-se com a implementação do capital financeiro no Brasil. O desembarque das multinacionais durante o governo JK, que então investiram nos setores de bens de consumo duráveis, e o início da construção do setor de bens de capital e da indústria de base com vultosos aportes estatais no governo Vargas, são constitutivos dessa fase do desenvolvimento capitalista brasileiro.

A transição econômica de uma fase para outra causou turbulência política. Vargas, então envolvido na luta nacionalista/anti-imperialista, suicidou-se para evitar um golpe orquestrado por forças reacionárias internas e externas. Logo depois, Juscelino Kubitschek, que operou a fusão de um novo bloco de poder no país - baseado no tripé burguesias internacionais, burguesia brasileira e Estado - , foi ameaçado de não tomar posse por conta de um golpe orquestrado pelos mesmos setores que tentaram derrubar Getúlio. Jânio Quadros renunciou ao seu mandato e João Goulart, que procurou aprofundar um projeto nacional-popular de reformas de base, foi deposto por um golpe civil-militar que instaurou a autocracia burguesa e consolidou o capitalismo financeiro no país.

Os grupos progressistas - dos trabalhistas aos comunistas, dos reformistas aos revolucionários ${ }^{4}$ - que apoiavam em maior ou menor grau o nacional-desenvolvimentismo foram derrotados e massacrados por uma ditadura civil-militar de vinte anos, e o desenvolvimentismo tomou novos rumos sob o tacão de ferro dos militares, da tecnocracia estatal e da burguesia, hegemoniza-

4. Antes do golpe de 1964, poucos grupos marxistas levantaram a voz contra o nacional-desenvolvimentismo. Uma das principais resistências político-ideológicas à hegemonia desenvolvimentista veio da Organização Revolucionária Marxista - Política Operária, que ficou conhecida pela sigla Polop. Para as críticas dessa organização ao nacional-desenvolvimentismo, cf. Polop (1960-2009, p. 25). Do seu seio, Ruy Mauro Marini, Theotônio dos Santos e Vânia Bambirra escreveriam um dos capítulos mais sugestivos do pensamento econômico brasileiro, a Teoria Marxista da Dependência. 
da pelos monopólios internacionais. O milagre veio, o bolo cresceu, mas a dependência e o subdesenvolvimento persistiram, e as desigualdades socioeconômicas aumentaram, com imensas perdas para a classe trabalhadora.

Diante desse cenário histórico de grandes transformações sociais, autores de distintas filiações políticas e ideológicas - Alberto Guerreiro Ramos, Álvaro Vieira Pinto, Caio Prado Jr., Celso Furtado, Darcy Ribeiro, Florestan Fernandes, Hélio Jaguaribe, Ignácio Rangel, Josué de Castro, Milton Santos, Nelson Werneck Sodré, Paulo Freire, Roberto Campos, Ruy Mauro Marini e outros ${ }^{5}$ - discutiram uma série de questões sobre a formação econômico-social brasileira, como a industrialização, a inserção do Brasil na divisão internacional do trabalho, o subdesenvolvimento, a dualidade, o Estado, as alianças políticas entre classes e grupos sociais, a educação, a fome, o território, as populações nativas etc.

Esse acalorado debate entrou para história do pensamento econômico como a controvérsia da revolução brasileira, ${ }^{6}$ na qual grupos e classes sociais ganharam voz nas obras dos seus representantes ideológicos e disputaram a direção intelectual-moral do país. A disputa entre liberais, desenvolvimentistas e marxistas foi intensa, e o nacional-desenvolvimentismo foi uma das ideologias mais proeminentes e merece ser aqui resgatada para uma posterior comparação com o novo desenvolvimentismo.

E o que defendiam os clássicos do nacional-desenvolvimentismo? Em primeiro lugar, tinham como ponto de partida as questões estruturais, levando em conta os múltiplos aspectos da realidade. É um equívoco colocar Celso Furtado na caixinha departamental da economia, ou Florestan Fernandes na da sociologia, Caio Prado na de historiador e assim por diante. Eles trabalharam a partir de uma perspectiva multidisciplinar, explicitando suas concepções do mundo e seus propósitos político-ideológicos. A neutralidade do cientista social, tão propugnada pelos positivistas, passou ao largo da controvérsia da revolução brasileira.

Em termos gerais, eles partiram das questões externas que envolvem o Brasil desde a sua fundação como colônia. Historicamente, o processo da

5. Um panorama introdutório a esses autores está presente no livro O Brasil em evidência: a utopia do desenvolvimento, organizado por Martins e Munteal, 2012.

6. Sobre a controvérsia da revolução brasileira no pensamento econômico brasileiro, cf. Rocha, 2011 e Castelo, 2011. 
nossa formação econômico-social é entendido como subordinado aos interesses das nações colonialistas e imperialistas. O sistema capitalista criou, sincronicamente, a partir das relações de exploração e dominação entre as nações do Norte e do Sul, o desenvolvimento do centro e o subdesenvolvimento da periferia, que teria como uma das suas marcas a dualidade entre setores produtivos (indústria e agricultura) e regiões (Sudeste e Nordeste). A dependência foi tratada como um elemento-chave da controvérsia, e os reformistas viram nas políticas nacionalistas de protecionismo econômico, controle cambial e restrição ao envio de lucros ao exterior uma saída para os nossos crônicos déficits na balança de pagamentos.

Considerado uma estrutura acima das classes sociais e das suas lutas, o Estado foi elencado pelos setores reformistas como o ator central das transformações necessárias para a superação do subdesenvolvimento, capaz de soldar interesses antagônicos dos trabalhadores e dos burgueses industriais, conciliando o inconciliável. Segundo as análises dualistas, o atraso (colonial, feudal e/ou semifeudal) seria uma barreira ao moderno (capitalismo) e precisava ser removido. Defendiam reformas típicas das revoluções democrático-burguesas, como a agrária, a tributária, a consolidação de leis trabalhistas (especialmente dos trabalhadores rurais), o direito ao sufrágio universal, a livre organização classista e um conjunto de políticas econômicas para a geração de emprego e aumento da massa salarial. Ou seja, as reformas da revolução democrático-burguesa tocariam em elementos estruturais do subdesenvolvimento, tendo como base social organizações da classe trabalhadora coligadas com setores progressistas da intelectualidade e com uma burguesia nacional, sob a bênção de um pacto social orquestrado e sancionado pelo Estado. Esta aposta desenvolvimentista para a ruptura com o atraso foi abortada pelo golpe de 1964. As ilusões sobre um passado feudal/semifeudal e da existência de uma mítica burguesia nacional - denunciadas por Caio Prado Jr., Florestan Fernandes, Octávio Ianni, Ruy Mauro Marini, Theotônio dos Santos - pagaram seu devido preço naquela conjuntura, que terminou com um trágico desfecho.

O pior é constatar que essas ilusões, derrotadas no passado no campo político-militar, voltam ao presente sob uma escola do pensamento econômico que retoma o antigo desenvolvimentismo com o prefixo "novo" (neo) sem 
algumas mediações históricas necessárias. A velha tragédia ganha, desta maneira, contornos de uma farsa contemporânea...

\subsection{0 novo desenvolvimentismo e suas correntes}

O neoliberalismo surgiu na América Latina com a instauração da autocracia burguesa nos anos 1970. Em 1973, a via chilena para o socialismo foi interrompida pelo golpe liderado pelo general Pinochet, que implementou medidas neoliberais propostas por economistas monetaristas da escola de Chicago. Em 1976, o golpe na Argentina fez algo parecido no campo da economia, bem como na violação dos direitos humanos. A segunda fase do neoliberalismo no continente ocorreu nos anos 1980, quando presidentes foram eleitos com uma plataforma tipicamente liberal. Desta forma, ao contrário dos anos 1970, o neoliberalismo (res)surgiu na região a partir de pleitos eleitorais da democracia representativa. A partir de então até o início do século XXI, a agenda política da região girou em torno do Consenso de Washington, que previa uma série de medidas para acabar com a crise da dívida externa, a estagnação econômica e os altos índices inflacionários. Em essência, as medidas do Consenso representaram a vitória político-cultural da burguesia rentista e prepararam o terreno para a inserção da América Latina na etapa contemporânea do imperialismo, na qual a região se torna uma plataforma de valorização dos capitais estrangeiros por meio de compras e expropriações maciças de bens públicos e da especulação financeira.

Já na década de 1990, os danos sociais da agenda neoliberal foram sentidos com maior intensidade. Brasil, México e Argentina viram cadeias dos parques produtivos ser desmontadas e alguns setores desnacionalizados. O desempenho macroeconômico foi pífio: baixas taxas de crescimento, desequilíbrios nos balanços de pagamentos (com graves crises cambiais), déficits públicos crescentes e aumento das dívidas públicas internas. E os efeitos sobre expressões da "questão social" também foram desastrosos: aumento do desemprego estrutural e do pauperismo (absoluto e relativo) e perda de direitos sociais básicos, como a precarização das relações trabalhistas e a privatização de bens públicos, como saúde, previdência e educação. 
Diante desses primeiros sinais do desgaste do neoliberalismo, percebeu-se uma dupla movimentação na política regional: de um lado, as classes dominantes readequaram o seu projeto de supremacia, incorporando uma agenda de intervenção focalizada nas expressões mais explosivas da "questão social", naquilo que se convencionou chamar de social-liberalismo; assim, a supremacia burguesa ganhou novo fôlego (que se mostra cada vez mais exaurido) e persiste até hoje. De outro, uma mobilização política das classes subalternas antagônica ao neoliberalismo levou à derrubada de governantes alinhados ao Consenso de Washington (Argentina, Bolívia, Equador, Peru) e à eleição de coalizações partidárias com posições antineoliberais (Venezuela, Brasil, Argentina, Bolívia, Equador, Uruguai). Em alguns casos, as lideranças não mantiveram a sua linha de resistência após a posse e aderiram ao neoliberalismo por intermédio do social-liberalismo: o governo Lula é o caso mais emblemático dessa adesão ao projeto de supremacia burguesa. Em outras situações, a resistência popular radicalizou-se e desencadeou processos guiados pelo socialismo del siglo XXI, como a revolução bolivariana na Venezuela.

O novo desenvolvimentismo surgiu no século XXI após o neoliberalismo experimentar sinais de esgotamento, e logo se apresentou como uma terceira via, tanto ao projeto liberal quanto do socialismo. Os primeiros escritos do novo desenvolvimentismo brasileiro apareceram no primeiro mandato do governo Lula no tinteiro de Luiz Carlos Bresser Pereira, ex-ministro da Reforma do Estado, professor emérito da FGV-SP e então intelectual orgânico do PSDB. Em 2004, Bresser Pereira publicou na Folha de S.Paulo um artigo intitulado "O novo desenvolvimentismo", no qual defendia uma estratégia de desenvolvimento nacional para romper com a ortodoxia convencional do neoliberalismo. Segundo seus apontamentos, o novo desenvolvimentismo se diferenciaria do nacional-desenvolvimentismo em três pontos: maior abertura do comércio internacional; maior investimento privado na infraestrutura e maior preocupação com a estabilidade macroeconômica. "Em síntese”, escreve Bresser Pereira (2004, p. 2-3), "o mercado e o setor privado têm, hoje, um papel maior do que tiveram entre 1930 e 1980: a forma do planejamento deve ser menos sistemática e mais estratégica ou oportunista, visando permitir que as empresas nacionais compitam na economia globalizada". O novo desenvolvimentismo brasileiro emergiu, portanto, do seio da intelectualidade tucana que implementou o neoliberalismo no país. 
Um ano depois, um grupo de acadêmicos lançou o livro Novo desenvolvimentismo (2005). Essa obra traz, majoritariamente, textos de intelectuais tradicionais alinhados ao estruturalismo cepalino e ao keynesianismo. Na apresentação do livro, os organizadores identificam afinidades com o artigo de Bresser Pereira, mas procuram ir além de sugestões de política macroeconômica, discutindo, por exemplo, temas como a relação mercado-Estado, na qual um Estado forte deve regular um mercado forte, estimulando a concorrência e a inovação para tornar "o capitalismo dinâmico e revolucionário" (Sicsú, Paula e Michel, 2005, p. XL). Além disso, os autores apostam em uma estratégia de desenvolvimento que compatibilize altas taxas de crescimento econômico com a equidade social, tema que não foi levantado no texto seminal de Bresser Pereira. Para isto propõem medidas de políticas macroeconômicas associadas a programas sociais de promoção de igualdade de oportunidades e reformas nos sistemas financeiros, educacionais e de inovação tecnológica.

Com pontos de convergência entre si, Bresser Pereira, João Sicsú e Cia. foram um dos primeiros a defender o novo desenvolvimentismo como um projeto político de superação do neoliberalismo, embora reconheçam a existência de similaridades entre as políticas econômicas neoliberais e neodesenvolvimentistas, como a defesa do equilíbrio fiscal e o controle inflacionário. Outros pontos em comum, como a defesa da equidade social e a promoção da igualdade de oportunidades, temas típicos do pensamento liberal, passam despercebidos. Para travarem o combate teórico, difundem sua ideologia por meio de aparelhos privados de hegemonia, como a FGV-SP, a Associação Brasileira Keynesiana e a Revista de Economia Política. Esses ideólogos lançaram uma velha ideia para os novos tempos, que rapidamente ganhou eco e transcendeu a academia, alcançando setores da burocracia estatal e mesmo do empresariado ligado a organizações como o Iedi e a Fiesp. ${ }^{7}$

A partir de então, o novo desenvolvimentismo ganhou fôlego com a publicação de obras e artigos acadêmicos e jornalísticos, a realização de seminários e a abertura de uma nova conjuntura nacional e internacional. Um grupo

7. Em setembro de 2011, o segundo vice-presidente da Fiesp, João Guilherme Ometto, afirmou que o Brasil precisa voltar para o nacional-desenvolvimento e defender sua indústria se quiser reduzir a dependência externa e crescer novamente a altas taxas. 
de intelectuais ligados ao PT tenta sustentar a tese de que uma inflexão nas políticas econômicas (Barbosa e Souza, 2010), sociais e externa no Brasil a partir de 2007-08 teria levado o país a romper com o neoliberalismo e viver uma época pós-neoliberal (Sader, 2011), uma grande transformação (Sader e Garcia, 2010) e/ou a emergência de um padrão de acumulação chamado de social-desenvolvimentismo, baseado na produção de bens e serviços e na distribuição equitativa da renda (Mercadante, 2010; Pochmann, 2010, Carneiro et al., 2012).

Aloizio Mercadante, atual ministro da Educação, é um dos defensores da tese do social-desenvolvimentismo, que, na sua opinião, consiste "no compromisso fundamental de impulsionar a constituição de um amplo mercado de consumo de massa, que promovesse a inclusão de milhões de brasileiros, universalizasse as políticas sociais básicas e resolvesse o drama histórico da concentração de renda e riqueza" (Mercadante, 2010, p. 36). Para isto, compilou uma massa de dados para provar que o social tornou-se o eixo estruturante do desenvolvimento econômico no governo Lula, ao contrário do ocorrido nas outras fases do desenvolvimentismo. ${ }^{8}$

Segundo Mercadante, os elementos centrais do novo desenvolvimentismo estariam previstos no documento "Um outro Brasil é possível", elaborado por economistas do PT para a eleição de 2002. Os autores defenderam uma ruptura com o neoliberalismo por meio de políticas de inserção soberana no mercado mundial, de inclusão social e de crescimento econômico orientado pelo planejamento estatal. Em 2002, em plena campanha presidencial, os analistas do PT refizeram sua análise de conjuntura e chegaram à conclusão de que a correlação de forças era desfavorável a uma ruptura, e anunciaram, por meio da "Carta ao povo brasileiro", uma "necessária revisão tática" de abdicar da ruptura e assumir "o compromisso com uma transição progressiva e pactuada" (Mercadante, 2010, p. 37). De 2003 a 2006, o governo Lula teria aceito sem maiores contestações as políticas neoliberais e, a partir de 2007-08, teria voltado ao projeto original do novo desenvolvimentismo.

\footnotetext{
8. Segundo Wladimir Pomar, o nacional-desenvolvimentismo teve quatro fases: governos Vargas, governo JK, ditadura militar e os governos do PT. Sobre as semelhanças e diferenças das fases do nacional-desenvolvimentismo na sua perspectiva novo desenvolvimentista, consultar o artigo "Desenvolvimentismos". Disponível em: <http://www.correiocidadania.com.br/index.php?option=com_content\&view=article\&id=4 267:pomar270110\&catid=14:wladimir-pomar\&Itemid=88>. Acesso em: 15 jul. 2012.
} 
Durante a sua presidência no Ipea, Márcio Pochmann assinou um sem-número de trabalhos autorais sobre desenvolvimento e trabalho no Brasil, além de ter reorientado a produção do instituto de pesquisa para temas de interesse nacional, colocando-o como um dos polos centrais da ideologia novo-desenvolvimentista. No capítulo II do livro Desenvolvimento, trabalho e renda no Brasil (2010), Pochmann elabora o conceito de social-desenvolvimentismo como um padrão de acumulação (ou modelo de desenvolvimento) que conjugaria crescimento econômico, reafirmação da soberania nacional (Brasil como credor mundial, acúmulo de reservas externas e diversificação de parceiros comerciais), reformulação do papel do Estado (reforço nas empresas e bancos públicos, aumento do funcionalismo público e o Programa de Aceleração do Crescimento - PAC) e choque distributivo (aumento do salário mínimo e dos gastos sociais - previdência, assistência, seguro-desemprego e abono salarial - e expansão do crédito para pessoas físicas).

Nos seus escritos, Pochmann (2010) reafirma que houve uma "transição do neoliberalismo para o modelo social-desenvolvimentista" (p. 41) ou, em outros termos, uma "interrupção da hegemonia das políticas neoliberais" (p. 52) e "o abandono das teses neoliberais" (p. 63). Os mecanismos para esta transição seriam, no seu entendimento, políticas macroeconômicas, sociais e externas operadas pelo PT a partir da máquina estatal após as eleições presidenciais, sem aprovações de reformas constitucionais ou de embates diretos com as forças de sustentação do neoliberalismo.

À vista do exposto por Mercadante e Pochmann, afirma-se que a interrupção ou abandono do neoliberalismo no Brasil teria ocorrido por meio de uma "transição progressiva e pactuada", ocultando com quem esse pacto foi feito. Vale dizer, o pacto foi selado com as novas e antigas classes dominantes (capital financeiro e suas novas frações rentistas e o agrobusiness) que participam do bloco de poder em posições de destaque, como a presidência do Banco Central, ministérios e autarquias, para garantir a governabilidade do país conforme a lógica dos dirigentes do PT. ${ }^{9}$

9. Paul Singer, secretário nacional de economia solidária entre 2003 e 2010 , declarou, em outubro de 2011, que a aliança do PT com o sistema financeiro e os latifundiários deu tranquilidade para Lula e Dilma governarem. A declaração de Paul Singer está disponível em: <http://www.cartamaior.com.br/templates/ materiaMostrar.cfm?materia_id=18697>. Acesso em: 15 jul. 2012. 
Em 2011, com financiamento do Ministério da Ciência e Tecnologia e do Ipea, cerca de vinte economistas heterodoxos, majoritariamente dos Institutos de Economia da UFRJ e da Unicamp, fundaram a Rede Desenvolvimentista. A coordenação da Rede está a cargo do Centro de Estudos de Conjuntura e Política Econômica (Cecon), dirigido por Ricardo Carneiro. Após a fundação da rede, uma dezena de professores da Unicamp escreveu o documento "O desenvolvimento brasileiro: temas estratégicos", no qual discutem a remoção de barreiras ao desenvolvimento brasileiro. Segundo as suas avaliações, os principais obstáculos seriam a crise internacional, a necessidade de combinar crescimento e preservação ambiental e a manutenção das taxas de crescimento a longo prazo. Para superá-los, os autores sugerem uma política econômica de incentivo aos investimentos públicos e privados, que seria sustentável com investimentos nas infraestruturas econômica e social, constituição de ramos industriais tecnologicamente avançados, mecanismos internos de financiamento de longo prazo e mudança no perfil do consumo popular (Carneiro et al., 2012, p. 4).

Todo o diagnóstico de superação das barreiras ao desenvolvimento está fundamentado na análise de quinze temas considerados estratégicos, sendo quatro no plano internacional (reformas dos sistemas monetário e de governança econômica, nova divisão internacional do trabalho e blocos regionais) e onze no nacional (agricultura, indústria, desenvolvimento regional, financiamento externo, mercado de capitais, intervenção estatal na economia, políticas sociais etc.). Assim estruturado, o documento apresenta-se como uma pauta político-ideológico do novo desenvolvimentismo para atuação no Estado ampliado brasileiro, seja nos aparelhos da política econômica, como o BNDES, ${ }^{10}$ presidido por Luciano Coutinho, um dos mais destacados defensores do novo desenvolvimentismo, seja nos aparelhos estatais de hegemonia,

10. O principal posto ocupado pelos novo-desenvolvimentistas na política econômica foi a presidência do BNDES, que se tornou um dos maiores bancos de investimentos do mundo. O BNDES é a agência de financiamento do capital monopolista estabelecido no país, e suas linhas de crédito bilionárias foram usadas para acelerar processos de centralização e concentração do capital nas mãos de investidores nacionais e internacionais, os chamados global-players. Essas grandes corporações multinacionais promovem a conquista de mercados externos ao redor de todo o planeta, com destaque para África e América Latina, o que levou alguns autores a falar novamente no subimperialismo brasileiro. Sobre este assunto, vale conferir o livro Empresas transnacionais brasileiras na América Latina: um debate necessário, vários autores, editado pela Expressão Popular em 2009. 
como o Ipea e a Unicamp, e os privados, como o Centro Celso Furtado, as revistas Carta Capital e Le Monde Diplomatique e a agência de notícia Carta Maior.

Essas são, em suma, as três principais correntes do novo desenvolvimentismo. A primeira pode ser chamada de macroeconomia estruturalista do desenvolvimentismo (Bresser Pereira e Gala, 2010). A ideia básica apresentada é a primazia do mercado e seus mecanismos de produção da riqueza, com uma atuação reguladora do Estado nas falhas de mercado, especialmente nas políticas cambiais e de juros, com destaque para a promoção das exportações.

A segunda corrente, chamada de pós-keynesiana, assemelha-se muito à primeira, sustentando o papel do Estado como redutor das incertezas do ambiente econômico para favorecer as tomadas de decisão de investimento do setor privado, variável responsável em larga medida pelo crescimento econômico. Cabe ressaltar que tanto a primeira quanto a segunda corrente advogam a tese da aliança do Estado com o mercado (leia-se o empresariado industrial) contra os rentistas, como se essa contraposição radical entre as frações da burguesia existisse em tempos de acelerada fusão dos diferentes ramos do capital (agrícola, bancário, comercial, industrial e rentista). Fala-se novamente em uma coalização nacional entre burguesia industrial nacional, burocracia estatal, setores médios e trabalhadores, com hegemonia dos primeiros dois grupos sobre os demais.

A última corrente é a social-desenvolvimentista, cujas propostas estão assentadas na afirmação do mercado interno via ampliação do consumo de massa. O Estado tem um peso maior nas propostas dessa corrente no que nas duas precedentes, e as políticas macroeconômicas devem ser subordinadas às de desenvolvimento.

O pensamento econômico brasileiro, a partir do novo desenvolvimentismo, recolocou em tela alguns grandes temas nacionais, como soberania externa, integração regional e inserção na divisão internacional do trabalho, industrialização e inovação tecnológica, distribuição de renda, nova classe média etc. Estes temas, todavia, aparecem em larga medida esvaziados do seu conteúdo crítico e analítico para justificar uma razão de governo. $\mathrm{O}$ debate dos novo-desenvolvimentistas é unilateralmente estabelecido com os neoliberais, 
ignorando-se uma ampla gama de trabalhos críticos à nova etapa do desenvolvimento capitalista brasileiro. ${ }^{11}$

Em termos políticos, como realizar a superação com um dos projetos de supremacia burguesia mais coesos da história moderna sem reformas ou revoluções? A despeito dos limites das lutas nacional-desenvolvimentistas, eles falavam em reformas estruturais com apoio popular, lutas anti-imperialistas e antilatifundiárias para pôr fim ao subdesenvolvimento. Hoje, o novo desenvolvimentismo reduz as lutas de classes ao controle das políticas externa, econômica e social para operar uma transição lenta e gradual do neoliberalismo para uma quarta fase do desenvolvimentismo. A grande política é, portanto, esvaziada do seu poder transformador, dando lugar a uma política de gestão técnica dos recursos orçamentários, ${ }^{12}$ como se a distribuição da riqueza nacional e a apropriação da mais-valia não se tratasse de uma questão de organização e força das classes sociais, tal qual defendiam a economia política clássica e a crítica da economia política. Conforme declara Luiz Werneck Vianna (2012, p. 5-6),

O que se tem hoje é uma tecnocracia animada pela aspiração de desenvolver, maximizar, robustecer o capitalismo brasileiro e inscrevê-lo de forma mais presente e vigorosa no cenário do capitalismo mundial. O nacional-desenvolvimentismo tinha uma conotação emancipatória, diferente de hoje. A conotação nacional desse desenvolvimentismo atual é fraca. $O$ tema forte nele é o desenvolvimento da ordem burguesa no Brasil.

No lugar do confronto e do dissenso, opera-se a entrada do novo desenvolvimentismo como uma força auxiliar e subalterna dentro do atual bloco de

11. Cf. Francisco de Oliveira et al. (orgs.) (2010), Leda Paulani (2008), Luiz Filgueiras e Reinaldo Gonçalves (2007), Paulo Passarinho et al. (2010), Valério Arcary (2011) e Virgínia Fontes (2010)

12. A tensão advinda das lutas de classes promovidas pelos trabalhadores ajuda a desmascarar o caráter classista do atual governo. Durante a greve das universidades federais, noticiou-se que o Estado brasileiro gasta cerca de $45 \%$ do fundo público com o pagamento de juros e amortizações da dívida e menos de $4 \%$ com a educação. Diante das exigências dos professores, técnico-administrativos e estudantes por melhores condições de trabalho e estudo e reestruturação das carreiras, o ministro Guido Mantega foi obrigado a se posicionar e declarou que o movimento grevista poderia quebrar o Estado caso os aumentos de recursos para a educação pública fossem concedidos (cf. $O$ Globo, 5 jul. 2012, p. 5). Recursos escassos para as políticas sociais públicas, abundantes para os rentistas: esta é a economia política da política econômica dos governos brasileiros na era neoliberal. 
poder, pois a máquina estatal ainda é dirigida pelos intelectuais do social-liberalismo encastelados no Banco Central, Ministério do Planejamento e Tesouro Nacional, que mantém de pé o Consenso de Washington mediado com algumas medidas do pós-Consenso - superávit primário (o investimento das estatais e do PAC foi retirado do cálculo do superávit, além de aportes de bilhões de reais do Tesouro nacional no BNDES), câmbio flutuante (administração de um piso mínimo com intervenções no mercado cambial para estimular as exportações e manter superávits na balança comercial) e metas inflacionárias (o objetivo é o teto, e não mais o centro das metas).

Abriu-se, assim, uma nova etapa da revolução passiva com acordos entre modernas e arcaicas classes dominantes sob a égide da aristocracia operária que abandonou seus projetos de socialismo antes mesmo de assumir o governo (Iasi, 2006, parte 2), em um processo maciço de transformismo. Consequentemente, nos deparamos com uma nova fase do capitalismo dependente: sem rupturas, reafirmou-se o desenvolvimento desigual e combinado brasileiro.

\section{50 anos em 5: a decadência ideológica do pensamento econômico brasileiro (à guisa de conclusão)}

A decadência ideológica do pensamento econômico brasileiro não começou com o novo desenvolvimentismo, muito menos na era neoliberal. Uma extensa pesquisa sobre o tema precisa ser realizada, mas pode-se dizer preliminarmente que o processo de esvaziamento das questões macroestruturais se aprofunda com a autocracia burguesa nos anos 1960. Um dos seus primeiros capítulos está no uso das teorias do capital humano importadas dos Estados Unidos para a explicação da desigualdade gerada pelo "milagre" econômico. Ao longo dos anos 1980, a inflação brasileira, tida por clássicos da literatura especializada (Furtado e Rangel) como decorrente de questões estruturais, foi tratada como um fenômeno essencialmente monetário pelas escolas econômicas ortodoxas.

Já na década de 1990, a decadência ideológica ganhou um novo impulso a partir da vitória da burguesia rentista com o governo FHC e o seu plano de 
estabilização macroeconômica. O debate que girava em torno do desenvolvimento reduziu-se ao núcleo central do controle da inflação. Os demais assuntos foram tratados como satélites que gravitavam na órbita do debate inflacionário. Assim sendo, as vitórias burguesas — realizadas por meio de contrarrevoluções ou revoluções passivas - sobre os setores reformistas e revolucionários traduziram-se, no plano teórico, em momentos da decadência ideológica do pensamento econômico nacional liderados pelos ortodoxos.

Esta decadência ideológica não foi, entretanto, algo exclusivo das correntes liberais e neoliberais. Ela também ocorreu na escola desenvolvimentista a partir da década de 1970 como apontam Ruy Mauro Marini e Plínio de Arruda Sampaio Jr. Marini (1992, p. 94-9) fala do auge e decadência do desenvolvimentismo na segunda metade da década de 1970 e primeira de 1980. Na mesma linha, Sampaio Jr. (2012, p. 11) declara que

a Escola de Campinas foi um esforço de superar as insuficiências da explicação da Cepal sobre a especificidade da industrialização brasileira. No entanto, a meu ver ela deu um passo atrás na reflexão crítica, pois, em vez de superar as deficiências do estruturalismo, acabou negando a própria problemática do subdesenvolvimento. Ao reduzir a reflexão sobre o desenvolvimento latino-americano ao processo de constituição de um sistema industrial e a problemática da industrialização tardia à internalização da indústria de bens de capital, o Capitalismo Tardio desvinculou desenvolvimento capitalista e integração nacional.

Nos últimos tempos, José Luís Fiori (2011a, 2011b e 2011c) debruçou-se sobre o desenvolvimentismo, tratando da decadência ideológica desta escola sem usar o conceito marxiano. ${ }^{13}$ Primeiro analisa o "desenvolvimentismo de esquerda" elaborado pelo PCB, Iseb e Cepal, e mostra a Escola de Campinas como uma tentativa de renovar e atualizar as interpretações sobre o capitalismo

13. A série de artigos de Fiori sobre o desenvolvimentismo recebeu uma réplica de Ricardo Carneiro ("Um intelectual no seu labirinto"), que contesta a versão da decadência ideológica da escola de Campinas. A polêmica entre Fiori e Carneiro é um dos pontos altos da controvérsia do novo desenvolvimentismo. A réplica de Carneiro está disponível em: <http://www.cartamaior.com.br/templates/materiaMostrar. cfm?materia_id=19890>. Acesso em: 15 jul. 2012. 
brasileiro, comparando-a com a escola da dependência nas suas vertentes originadas dos trabalhos de André Gunder Frank e Fernando Henrique Cardoso (Fiori, 2011b). O balanço de Fiori (2011c) é que a teoria da dependência deixou um legado que abalou os fundamentos do "desenvolvimentismo de esquerda", que nunca mais conseguiu "se refazer do golpe" nem "construir uma nova base teórica que possa dar um sentido de longo prazo às suas intermináveis e inconclusivas deblaterações macroeconômicas, e ao seu permanente entusiasmo pelo varejo keynesiano". Sobre o tempo presente, Fiori estabelece a genealogia do novo desenvolvimentismo com a Cepal e a Escola de Campinas, e chega à conclusão que a atual escola desenvolvimentista

trata-se de um pastiche de propostas macroeconômicas absolutamente ecléticas,
e que se propõem fortalecer, simultaneamente, o estado [sic] e o mercado; a cen-
tralização e a descentralização; a concorrência e a política fiscal e monetária, que
seja ao mesmo tempo ativa e austera. E, finalmente, com relação ao papel do
estado [sic], o "neo desenvolvimentismo" propõe que ele seja recuperado e for-
talecido mas não esclarece em nome de quem, para quem e para quê, deixando
de lado a questão central do poder, e dos interesses contraditórios das classes e
das nações. (Fiori, 2011a)

Por fim, Sampaio Jr. (2012, p. 12) é contundente em afimar que "o neodesenvolvimentismo é um rótulo oco. É muito mais uma estratégia de propaganda dos governos Lula e Dilma, no seu afã de se diferenciar dos governos FHC, do que num corpo de doutrina para orientar a ação do Estado. Não conheço nenhum trabalho sério que explique as bases objetivas e subjetivas desse novo desenvolvimentismo".

O novo desenvolvimentismo fez, portanto, um duplo movimento para reforçar a decadência ideológica do pensamento burguês: ignorou as críticas marxistas de Caio Prado Jr., Florestan Fernandes, Octávio Ianni e da teoria da dependência (Marini, Bambirra, Gunder Frank, dos Santos) realizadas nos anos 1960-70 ao nacional-desenvolvimentismo, críticas que representam uma fase áurea do pensamento social brasileiro, e esvaziou — teórica e politicamente - as contribuições clássicas do nacional-desenvolvimentismo sobre a teoria do valor-trabalho (produção, tecnologia e excedente), a vulnerabilidade externa, 
o subdesenvolvimento, a dependência e a revolução brasileira, destruindo em pouco mais de cinco anos uma reputação que os clássicos do nacional-desenvolvimentismo construíram ao longo dos últimos cinquenta.

Recebido em 2/8/2012 - Aprovado em 14/8/2012

\section{Referências bibliográficas}

ARCARY, Valério. Um reformismo quase sem reformas: uma crítica marxista do governo Lula em defesa da revolução brasileira. São Paulo: Sundermann, 2011.

BARBOSA, N.; SOUZA, J. A. P. de. A inflexão no governo Lula: política econômica, crescimento e distribuição de renda. In: SADER, E.; GARCIA, M. A. (Orgs.). Brasil: entre o passado e o presente. São Paulo: Fundação Perseu Abramo, Boitempo, 2010.

BIELSCHOWSKY, Ricardo. Pensamento econômico brasileiro: o ciclo ideológico do desenvolvimentismo. 2. ed. Rio de Janeiro: Contraponto, 1995.

BRESSER PEREIRA, Luiz Carlos. O novo desenvolvimentismo. Folha de S.Paulo, 19 set. 2004. Disponível em: <http://www.bresserpereira.org.br/articles/2004/412.NovoDesenvolvimentismo.pdf $>$. Acesso em: 28 jul. 2012.

; GALA, P. Macroeconomia estruturalista do desenvolvimento. Revista de Economia Política, v. 30, n. 4, p. 663-680, 2010.

CARNEIRO, R. et al. O desenvolvimento brasileiro: temas estratégicos. Disponível em: $<$ http://www.reded.net.br/index.php?option=com_jdownloads\&Itemid=419\&view $=$ finish\&cid=160\&catid=14\&lang=pt $>$. Acesso em: 28 jul. 2012.

CASTELO, Rodrigo. O novo desenvolvimentismo e a decadência ideológica do estruturalismo latino-americano. In: (Org.). Encruzilhadas da América Latina no século XXI. Rio de Janeiro: Pão e Rosas, 2010.

. Florestan Fernandes: subdesenvolvimento, capitalismo dependente e revolução no pensamento econômico brasileiro. In: MALTA, Maria Mello de (Coord.). Ecos do desenvolvimento: uma história do pensamento econômico brasileiro. Rio de Janeiro: Ipea; Centro Celso Furtado, 2011.

COUTINHO, Carlos Nelson. Gramsci: um estudo sobre seu pensamento político. 2. ed. Rio de Janeiro: Civilização Brasileira, 1999. 
FILGUEIRAS, L.; GONÇALVES, R. A economia politica do governo Lula. Rio de Janeiro: Contraponto, 2007.

FIORI, José Luís. A miséria do "novo desenvolvimentismo". 2011a. Disponível em: $<$ http://www.cartamaior.com.br/templates/colunaMostrar.cfm?coluna_id=5334>. Acesso em: 15 jul. 2012.

. O desenvolvimentismo de esquerda. 2011b. Disponível em: <http://www. cartamaior.com.br/templates/colunaMostrar.cfm?coluna_id=5495>. Acesso em: 15 jul. 2012.

. Desenvolvimento e dependência. 2011c. Disponível em: <http://www.cartamaior.com.br/templates/materiaMostrar.cfm?materia_id=19889>. Acesso em: 15 jul. 2012.

FONSECA, Pedro Dutra. Gênese e precursores do desenvolvimentismo no Brasil. Pesquisa \& debate, São Paulo, v. 15, n. 2, p. 225-256, 2004.

FONTES, Virgínia. O Brasil e o capital-imperialismo: teoria e história. Rio de Janeiro: EPSJV; UFRJ, 2010.

IASI, Mauro. As metamorfoses da consciência de classe: o PT entre a negação e o consentimento. São Paulo: Expressão Popular, 2006.

INSTITUTO ROSA LUXEMBURGO et al. (Orgs.). Empresas transnacionais brasileiras na América Latina: um debate necessário. São Paulo: Expressão Popular, 2009.

LUKÁCS, György. Marx e o problema da decadência ideológica. In: . Marxismo e teoria da literatura. 2. ed. São Paulo: Expressão Popular, 1938-2010.

MALTA, M.; CASTELO, R. Marx e a história do pensamento econômico: um debate sobre método e ideologia. In: GANEM, Angela et al. (Orgs.). Economia e filosofia: controvérsias e tendências recentes. Rio de Janeiro: Editora da UFRJ, 2012.

MARINI, Ruy Mauro. América Latina: dependência e integração. São Paulo: Brasil Urgente, 1992.

MARTINS, Paulo Emilio Matos; MUNTEAL, Oswaldo (Orgs.). O Brasil em evidência: utopia do desenvolvimento. Rio de Janeiro: FGV, 2012.

MARX, Karl. Para a crítica da economia política. São Paulo: Abril Cultural, 1859-1982. . O rendimento e suas fontes. São Paulo: Abril Cultural, 1862-3-1982.

. O capital: crítica da economia política. Livro I. 21. ed. Rio de Janeiro: Civilização Brasileira, 1867-2003. 
MARX, Karl. Posfácio à segunda edição alemã. In: $O$ capital: crítica da economia política. Livro I. 21. ed. Rio de Janeiro: Civilização Brasileira, 1873-2003.

MERCADANTE, Aloizio. Brasil: a construção retomada. São Paulo: Terceiro Nome, 2010 .

NAPOLEONI, Claudio (Org.). O futuro do capitalismo. Rio de Janeiro: Graal, 1982.

OLIVEIRA, F. de et al. (Orgs.). Hegemonia às avessas. São Paulo: Boitempo, 2010.

PAULANI, Leda. Brasil Delivery. São Paulo: Boitempo, 2008.

PASSARINHO, P. et al. Os anos Lula: contribuições para um balanço crítico 2003-2010. Rio de Janeiro: Garamond, 2010.

POCHMANN, Marcio. Desenvolvimento, trabalho e renda no Brasil: avanços recentes no emprego e na distribuição dos rendimentos. São Paulo: Fundação Perseu Abramo, 2010 .

POLOP. Convocatória para o $1^{\circ}$ Congresso da Polop. In: Polop: uma trajetória de luta pela organização independente da classe operária no Brasil. Salvador: Centro de Estudos Victor Meyer, 1960-2009.

ROCHA, Marco Antonio da. Revolução Brasileira, dualidade e desenvolvimento: do nacional-desenvolvimentismo à Escola de Sociologia da USP. In: MALTA, Maria Mello de (Coord.). Ecos do desenvolvimento: uma história do pensamento econômico brasileiro. Rio de Janeiro: Ipea; Centro Celso Furtado, 2011.

SADER, Emir. Neoliberalismo versus pós-neoliberalismo: a disputa estratégica contemporânea. Margem Esquerda, n. 16, p. 123-127, 2011.

; GARCIA, M. A. Apresentação. In: (Orgs.). Brasil: entre o passado e o futuro. São Paulo: Fundação Perseu Abramo, Boitempo, 2010.

SAMPAIO Jr., Plínio de Arruda. Vivemos um processo de reversão neocolonial. IHU Online, n. 392, 2012. Disponível em: <http://www.ihuonline.unisinos.br/media/pdf/ IHUOnlineEdicao392.pdf>. Acesso em: 15 jul. 2012.

SICSÚ, J.; PAULA, L. F. de; MICHEL, R. (Orgs.). Novo desenvolvimentismo: um projeto nacional de crescimento com equidade social. Barueri/Rio de Janeiro: Manole/ Fundação Konrad Adenauer, 2005.

VIANNA, Luiz Werneck. A modernização brasileira e a política burguesa cinzenta. IHU On-line, n. 392, 2012. Disponível em: < http://www.ihuonline.unisinos.br/media/ pdf/IHUOn-lineEdicao392.pdf>. Acesso em: 15 jul. 2012. 